\title{
Identity, "Third Eye", Darwinian Survival and Competitive Unconscious: A global, empirical Survey
}

\author{
Foo Check Teck*
}

Associate Professor of System and Engineering Management Division, Mechanical and Aerospace Engineering School, Nanyang Technological University, Singapore; Professor \& Honorary Chair of Competitive Strategy, School of Management, University of St Andrews, UK.

\begin{abstract}
What is the raison d'etre for corporate e-identity? Why do even highly successful corporations continually emphasize their corporate presence in the marketplace? That their presence is felt visually by consumers through mega dollars advertisements of their most innovative product? In this paper we argue that deep in the soul or psyche of human beings there remains an unconscious that ensures Darwinian survival through emphasizing presence. Interestingly, Renes Descarte argued that the seat of our soul to be traceable to the pineal gland or proverbial "third eye". Extending our work along this line of inquiry we investigated empirically, the eye as motif for branding in corporate e-identity strategy. Results are reported which inter alia suggested for some the symbolic role of eye which extends beyond "seeing": an "inner vision" ("third eye"), one of the inner consciousness, the soul. This led to a final discussion on role of the competitive unconscious and corporate e-identity.
\end{abstract}

* FOO Check Teck wishes to thank the research assistance by Mohamed Halil bin Mohamed Ibrahim.

\section{RAISON D'ETRE OF CORPORATE E-IDENTITY}

\section{What is the Raison D'etre for Corporate E-Identity?}

Or to put it across in another manner: Why do corporations continue on reiterating their corporate e-identity through advertising in the marketplace? Even for corporations that are already household names, such as Nike (shoes), Nokia (hand-phones), Samsung (electronics), Toyota (cars) and more. Let us take a look at scholarly approaches to the study of corporate e-identity. Well known scholars researching on corporate e-identity (for example, Balmer, 2001) tends to view corporate e-identity alongside efforts in branding and marketing. Kapferer (2004) sees in e-identity building through strategic branding efforts from the perspective of longer term, financial viability.

Recent empirical analyses of publicly listed corporations across the ASEAN region (Foo, Lowe and Foo; 2001) reinforce this view that corporate e-identity had roles of enhancing the financial vitality of listed corporations. This is not surprising for the continued presence of chairman, board of directors and key managers in publicly listed corporations are dependent on returning good financial performances. Whilst financial indicators as in the daily share prices and their trends as well as related ratios (price/earnings) are obviously important, there is perhaps another even more critical perceptual measure: public perceptions of corporate unique capability in adapting to fast changing, highly competitive environments.

\footnotetext{
*Address Correspondence to this Author Mechanical and Aerospace Engineering School, Nanyang Technological University, Singapore; Professor \& Honorary Chair of Competitive Strategy, School of Management, University of St Andrews, UK; Tel: (65) 9790 9138; Fax: (65) 6792 1911;

E-mail:mctfoo@ntu.edu.sg
}

Good financial performances result from corporate capabilities in bringing to markets, winning products. Conversely, an inability to continuing to do so, for example currently the well-known case of Sony will result in sluggish financial results. Generating the right product embedded with the right technology, at the right time, right price and right market are to stakeholders - shareholders, customers, staff, suppliers and distributors - the clearest signals of top managerial capability in adapting to ever fast changing environments. One of the main reasons why large, already established names are continually spending huge sums of advertising dollars is to reiterate corporate Darwinian, adaptive capability. As illustrated through the example of dinosaurs, Darwinian survival is independent of size. What matters is in the ability of a species to adapt. We like here to introduce the perspective of an unconscious (instinctive) rationale for corporate e-identity. That is one of communicating to key stakeholders their adept Darwinian survival skills as possessing the fittest capability. For in Darwinian terms, survival is measured simply by presence. So extinction of a brand's next generation product is the Darwinian measure of failure to perform.

Customers equate corporate e-identity by sensing her presence. And of all the senses, the visual too is evidently the most crucial for survival. For in Darwinian terms, for animals to avoid being preys, they had to quick in sensing (especially in seeing) danger. The central role of the visual for corporate e-identity is mirrored too in the overwhelming numbers of visual and especially graphic specialists in practice. Their expertise is being tapped to intensify the effectiveness of corporate logos in communicating their presence. Recently Schroeder (1998) coined most appropriately, the phrase "consuming representation". He argued for a more visual approach in consumer research. In a later work, he highlighted the rise of "attention" economy (Schroeder, 
2002) and given the internet, that business had turned imagebound. Such a role for the visual in corporate e-identity building is also reflected in recent trend of growing published empirical research studies.

Pamela and her team (Pamela et al. (2004)) investigated such minute details as in the nature of design in typefaces. That is after she having had investigated (Pamela et. al. (2003)) into how branding is may be strengthened via the selection of certain visual components. Besides research interest, there is also the narrowing of focus of those in providing visually related services. For example, of the many visual consultants who made a specialty out of manipulating the graphic design of a $\log$, whether it is in its shape, color, thinness, fineness or thickness of lines, circles, triangles or dots. Arguably these highly intensive efforts in design process, one of refining, adapting of logo to our visual senses must be for a deeper purpose. The explanation we suggest is that our environments had become hypercompetitive. Thus "seeing" is being highly yet perhaps unconsciously emphasized in our society. For in it lies one or even the key to corporate survival. With such remarkable growth in the utilization of specialists in graphically rendering symbols for promoting their corporate identities, it is surprising for there to be a paucity of related, empirical research. There are examples of systematic, experimental studies of logos as may be seen in:

(1) Dimensionalities embedded in the design of e-logo (Foo, 2001)

(2) Experimentally testing on visual complexity (Foo, 2003) and

(3) Creativity (Foo, 2003) of logos, also through experiments.

Besides the visual aspects, the symbolic power underlying a $\log$ o is equally important. The enabling of corporate symbolism had being explored by Foo (2003) especially within the context of large, publicly listed corporations. One possible reason why there is such a corporate focus on the logo - whether is just a wriggle or lines - may lie in the 'power' of the logo to function also as a corporate symbol. Empirical studies ought to have been implemented to explain why a certain symbol is being employed for corporate expression. Much more in-depth research is required to unravel the processes of corporate e-identity building (Foo and Lowe, 1999). In particular, the rationale for choice of motifs in logos ought to become an integral part of research into corporate e-identity strategy. As argued earlier, increasingly to survive in hypercompetitive marketplaces, securing an immediately recognizable e-identity is almost a necessity. Arguably, a stronger e-identity puts a firm is at an edge sharper and fitter in battling for survival in the Darwinian jungle. Titling their work as The Expressive Organization, Schultz, Hatch and Larsen (2000) argue that:

“...Emotional and symbolic expressiveness is becoming part of the experience of doing business..." [Italics added].

Even more intriguingly they had argued in lines before this:

"The behavior that supports a corporate reputation or brand needs to be more deeply rooted; it needs to rest in the organization's e-identity." [Again, italics added].
Since the roots of our expressive behavior spring from deep down within our soul, the unconscious, we turn to review briefly Western explorations on the theory of the unconscious. In the process we found it necessary for the sake of completeness to introduce the "third eye" which Descartes (see later discussion) posited as being the very seat of our soul.

\section{THEORY OF UNCONSCIOUS AND THIRD EYE}

In his monumental work, Ellenberger (1970) reviewed early Western contributions to what he saw as the discovery of the unconscious. The title implies that even though the unconscious is always with us, we remain largely unaware of its roles and presence. This explains why within the literature of corporate e-identity there is hardly any mention of the unconscious. For corporate e-identity especially with regard to choice of motifs for logos and its design are so obviously conscious activities. Yet scholars like Schultz, Hatch and Larsen (see earlier discussion) had sensed there is more to mere expressiveness. That beneath all the visible, consciousness that gives rise to visible 'expression' must lay something deeper. That there is a level of the mind that is more profound than the conscious and it still remains even today a largely uncharted territory. Through this work, we wish to draw scholars to the possibility of Darwinian, competitive unconscious behind efforts to build corporate e-identity.

For the $20^{\text {th }}$ century, two psychoanalysts, Freud and Jung stood out and their works are popularly quoted, cited and with internet sites devoted to their works: Freud, the founding father of psycho-analysis introduced from the dichotomy of conscious-unconscious the concepts of the ego-idsuperego. Jung's approach is far more complex, he introduces concepts such as the collective unconscious and archetypes. It is however earlier works interest us. Through this exercise we get a glimpse of how Western men, mainly psychiatrists set about theorizing the unconscious. In the early $19^{\text {th }}$ century, Arthur Schopenhauer equated in The World as Will and Representation (1819), the human will as being synonymous with the unconscious. In essence what Schopenhauer had argued was that the irrationality of man is due mainly to those dark, deeply buried forces of the unconscious. These are influences that man himself is hardly even aware of. Carl Gustav Carus (1846) in his work, Psyche first put forward a theory of the unconscious. It is Dessoir (1890) who in reflecting on the human mind argued for the double ego. In his terminology, there is an upper consciousness and under-consciousness (presumably unconscious). An even more interestingly contribution lies in the work of Theodore Flournoy (1899) who explored the unconscious origin of messages that were initially thought to originate from the spiritual realm. For our purpose the most intriguing insight is that of Theodor Lipps (1896) who argued that past representations are active in oneself without one being aware of their presence and activity. It is he who drew up the metaphor of the unconscious as submerged mountains whilst the conscious are but exposed peaks. Using such an analogy he argued that the unconscious to be the question of psychology. In a similar vein, we theorize here that the competitive unconscious to be at the deepest source for the raison d'etre in corporate e-identity efforts. That may be why even already highly successful corporations are so driven to keep reiterating their corporate e-identity. Often it is by re-expressing 
anew via aggressive advertising campaigns. For they instinctively knew to survive in highly competitive Darwinian landscape, they had to sustain a strong visible, highly expressive corporate presence.

Besides the unconscious mind, there is yet another interesting insight that is relevant from my survey of the literature. It is one that harked back to the $17^{\text {th }}$ century and in the writings of Rene Descarte (1649). Spread across his letters, his very first work the Treatise of Man (before 1637; see Hall (1972)) as well as his last book "The passions of the soul" (1649), Descarte discussed about the role of the pineal gland. In his view the pineal gland given its centrality in the brain (see diagram below) is the very seat of the human soul. If so, then we may speculate a role for the pineal gland. That here lies possibly be the biological organ that is deeply rooted to our visible expressiveness towards corporate eidentity. If it is as Descrate theorized, the seat of the soul, then pineal gland may too be that deeper source to what Schultz, Hatch and Larsen (see earlier discussion) had mentioned about behaviors that ground deeply for us our identities. An even more interestingly perspective given our focus on corporate e-identity as visual symbols is the belief of the pineal gland as our dormant 'third eye'.

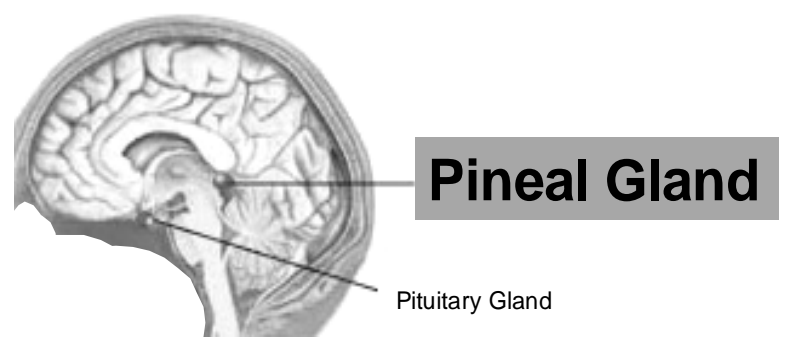

Fig. (1). "Third Eye" --- Pineal Gland.

In modern textbooks on psycho-biology (see for example, Goodson (2003)), the pineal gland is said to be an eye:

“...The pineal gland functions as a third eye in certain primitive amphibian..." (italics added; page 52, Goodson).

Indeed in our empirical research into firms utilizing the motif of the eye for logos, we found examples of respondents who clearly adopt this third eye as their corporate symbol. Still some who reduced their firm eidentity as being represented by the eye alone: Blumenfeld (1999) had put it most eloquently, "Eye to I". For some it is more than just the literal "seeing". Is it a "seeing" accompanied with knowledge. Take the case of art, it had been said for truly appreciating art, you should develop the painter's eye (Greenberg, (1991)). Documentary photographer Walker Evans (Mora, (2004)) had been described as having possessed the "hungry eye" whilst Deakin's eyes (Muir, (2002)) are dubbed to belong to those of a maverick. Van Gogh (Bonafoux (1992)) is said to possess such "passionate eyes". Clearly it is more than just the human eyes that these comments are alluding to. Our human eyes especially their movements being subjects of study through precise measurements (Duchowski, (2003)). Even more intriguing are references to the eye in a metaphorical sense as for example in major literary works. Titles such as these are highly suggestive of the symbolic power of the eye in conveying mean- ings: 'The needle's eye' (Drabble, (1973); Trollope's 'Eye for an eye' and White's 'The eye of a storm'. Then there is in financial circles of reference to achieving the "bull's eye" in investing (Mauldin (2004)). For these reasons, one can also expect corporate branding specialists whether as graphic designers or corporate e-identity strategists to be fascinated by the symbolism of the eye.

\section{EMPIRICAL INVESTIGATION OF EYE AS SYMBOL}

Despite the vital importance of the visual in corporate eidentity efforts, so far no one has investigated the eye as a symbol for corporate branding. Our research interests then in $2002 / 3$ are to focus on the rationale for using the eye as a motif in corporate branding efforts. These questions that motivated us:

1. Is the eye utilized as a symbol by itself?

2. Are words added for better communications?

3. Is the eye chosen to reflect the business?

4. Is any designer involved in the process?

5. Is the choice of the eye a personal decision?

6. Is the process, long and involved?

7. Is there a 'psychology' for employing the eye?

On (7), it was Arnheim (1974) who suggested there possibly be a psychology concerning the creative eye. Here we are investigating the eye from the perspective of its role as a visual symbol.

We utilized the internet to investigate the rationality behind the use of eye as part of the symbolism in corporate branding. In particular we retrieved eye logos through the search engine of www.google.com, an American-based search engine.

Many more eye logos may be available in cyberspace but these are not retrievable via Google. Our sample obtained however is adequate to satisfy our objective of gaining some empirical insights to utilizing the eye in branding for corporate e-identity. The statistical distribution of our 'population' is provided for in Table (1). As may be seen, out of the total, globally oriented population of firms $(\mathrm{N}=250)$, the predominant group is from the U.S. $(62 \% ; n=155)$ followed by U.K. $(8.4 \%, n=21)$, Germany $(4.8 \% ; n=12)$, Australia $(4 \% ; n=10)$, Canada $(3.6 \% ; n=9)$, Japan $(2.8 \% ; n=7)$, New Zealand and Ireland $(1.6 \% ; n=4$, each), France, Greece and Spain $(1.2 \%$; $\mathrm{n}=3$, each) and Norway, Russia and South Africa (0.8\%; $\mathrm{n}=2$, each) with the rest of the world $(0.4 \% ; \mathrm{n}=1$, each country). Using this as a sampling frame, we then queried them on their rationality for adopting the eye as a motif as logo. Also we were to uncover the processes behind the design of the eye-embedded e-logos (see discussion later). Through repeated e-mailings, we obtained a response rate of $21.6 \%$ $(n=54)$. We are much encouraged by the comments of some of the respondents who are themselves clearly intrigued by this research:

"This is a very interesting topic for a project".

Another put it as: “...an interesting project you have there..."

Then there is a respondent who remarks as follows: “...The results of your research would be very interesting if you care to share it..." 
Table 1. Global Sample

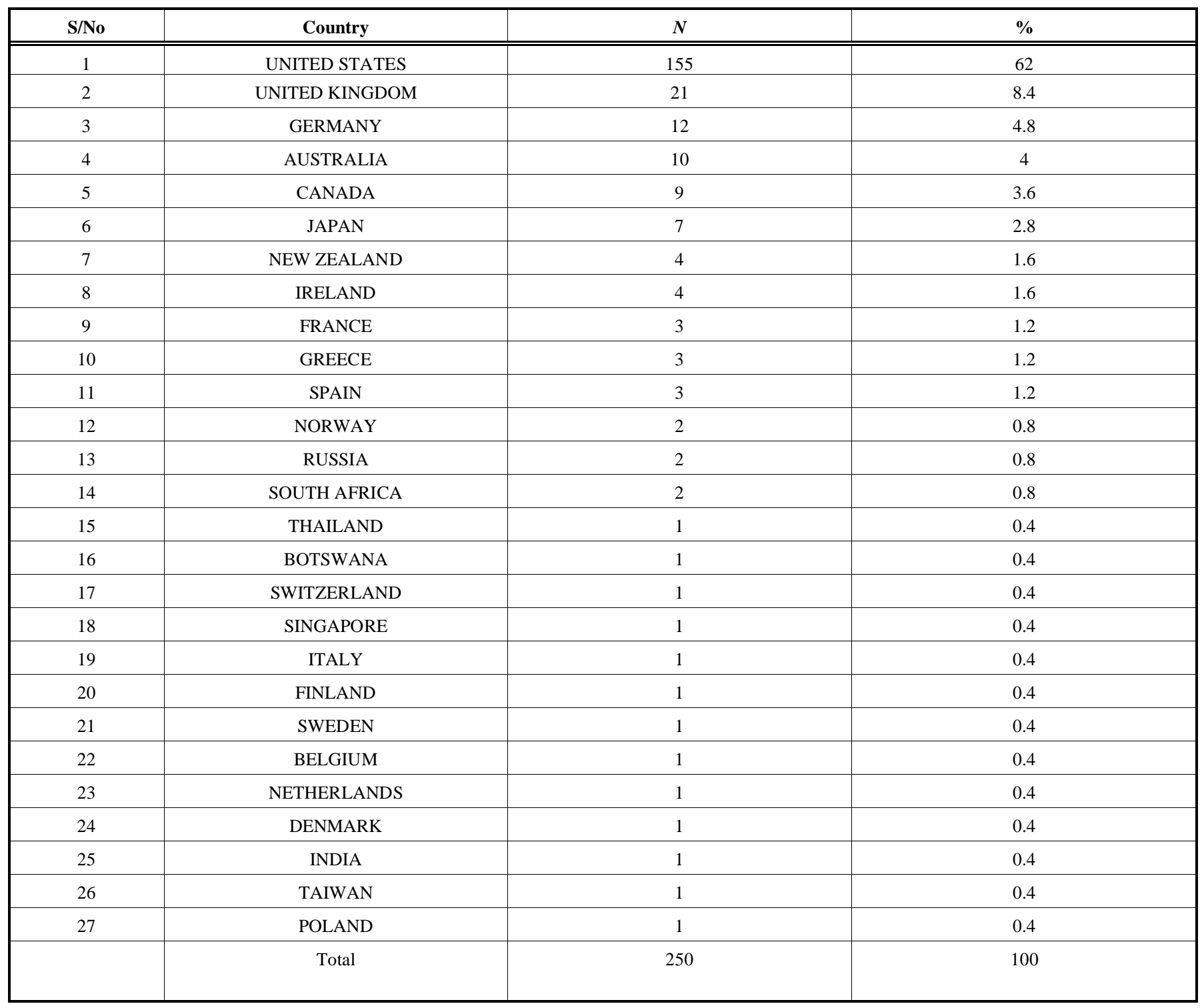

These remarks reinforced our belief that this in an intriguing area of research in the field of corporate e-identity and branding. Before we discuss on the psychology behind the choice of the eye, we provide the key statistical results based on analysis of responses received to our research questions.

\section{STATISTICAL RESULTS}

\section{The Logo Per Se}

Research Question: Is the eye utilized as a symbol by itself?

Our visual study of the e-logos suggests that the eye whether human or abstract is often utilized by itself to symbolize the firm. To our surprise we find as high as $35.2 \%$ (see Table (2) (i) of the respondents $(n=19)$ are using just the eye.

Research Question: Are words being added for better communication?
As to words used alongside the eye symbol we find this in exactly half $(50 \%$; $n=25)$ of the cases (see Table (2) (ii)). In other words, half the time, the "eye" alone is found to be sufficiently communicative. A more sophisticated explanation is that words may delimit the scope of interpretation by viewers as to the eye symbol. Like a piece of art, multiple interpretations are to be fostered.

Research Question: Is the eye chosen to reflect the business?

As anticipated, as many as $64.2 \%(n=34)$ chose the eye for reasons of relatedness to profession, business or industry (see Table (2) (iii)). Yet as shall be seen later there are many facets to this. These facets are unveiled in our in-depth discussion of the rationality for the choice of the eye as corporate symbol.

\section{The Process of Design}

Equally as intriguing is the process of design. Such fundamental issues in corporate branding as whether the choice 
Table 2. Symbolism of Eye

\begin{tabular}{|c|c|c|c|c|c|}
\hline \multicolumn{6}{|c|}{ (i) Only the Eye } \\
\hline \multirow{7}{*}{} & Frequency & Percent & $\begin{array}{c}\text { Valid } \\
\text { Percent }\end{array}$ & $\begin{array}{c}\text { Cumulative } \\
\text { Percent }\end{array}$ \\
\hline \hline \multirow{4}{*}{ Valid } & No & 35 & 64.8 & 64.8 & 64.8 \\
\cline { 2 - 6 } & Yes & 19 & 35.2 & 35.2 & 100.0 \\
\cline { 2 - 6 } & Total & 54 & 100.0 & 100.0 & \\
\hline
\end{tabular}

\begin{tabular}{|l|c|c|c|c|c|}
\hline \hline \multicolumn{6}{|c|}{ (ii) With Words } \\
\hline \multirow{3}{*}{} & Frequency & Percent & $\begin{array}{c}\text { Valid } \\
\text { Percent }\end{array}$ & $\begin{array}{c}\text { Cumulative } \\
\text { Percent }\end{array}$ \\
\hline \hline \multirow{3}{*}{ Valid } & No & 27 & 50.0 & 50.0 & 50.0 \\
\cline { 2 - 6 } & Yes & 27 & 50.0 & 50.0 & 100.0 \\
\cline { 2 - 6 } & Total & 54 & 100.0 & 100.0 & \\
\hline \hline
\end{tabular}

\begin{tabular}{|c|c|c|c|c|c|}
\hline \multicolumn{6}{|c|}{ (iii) Related to Business } \\
\hline & & Frequency & Percent & $\begin{array}{l}\text { Valid } \\
\text { Percent }\end{array}$ & $\begin{array}{c}\text { Cumulative } \\
\text { Percent }\end{array}$ \\
\hline \multirow{3}{*}{ Valid } & No & 19 & 35.2 & 35.8 & 35.8 \\
\hline & Yes & 34 & 63.0 & 64.2 & 100.0 \\
\hline & Total & 53 & 98.1 & 100.0 & \\
\hline Missing & & 1 & 1.9 & & \\
\hline \multicolumn{2}{|c|}{ Total } & 54 & 100.0 & & \\
\hline
\end{tabular}

Note: Statistical tables as generated by SPSS.

of a symbol is a personal decision or does it involve a specialist in the graphic design work. ess?

Research Question: Is any designer involved in the proc-

Very interestingly, the proportion is almost equal. The exact statistics is $49 \%(\mathrm{n}=25)$ for designer involvement (see Table (3) (i)). Due perhaps to its obviousness or simplicity, the eye logos are often designed by the owners $(51 \% ; n=26)$ themselves.

Research Question: Is the choice of the eye a personal decision? sion.

The result is almost an even split: $51 \%$ for personal deci-

Research Question: Is the process, long and involved?

Up to as high as $25.9 \%(n=14)$ of the sample reported the eye logo to result from a long, evolutionary process. Clearly these owners of businesses care deeply about their e-logos as part of their corporate branding strategy.

Next we explore the psychological rationale for using the eye in corporate branding.

\section{Psychological Rationale for the Symbolic Eye in Brand- ing}

\section{(1) Eye as integral to product/corporate name}

Our analysis suggests there are psychological roots to the choice of a symbol for logo in corporate branding. For example, one rationale for the eye as a symbol lies in its association with a product or corporate name. This is the case of the eye used to correspond with "Magick Eye Records". Yet in another case, there is an even deeper psychological explanation: deepening of corporate memory. For another respondent, the symbol of the eye-in-the-pyramid as a logo is chosen as it for its "historical association with Illuminati - one of our first hit games..." Such a finding suggests in a fastmoving, hyper-competitive product market scenario, owners have a psychological need for symbols to root them with their past, especially if they had been successful before. This suggests clearly a psychological role for symbols, one of reassuring owners of their capabilities or in Darwinian terms, their fitness to survive.

The association with a product(s) or corporate name may not be visually obvious but implied by 'sound'. For example, the sound of "eye" is identical to "I". Thus one respondent explains the situation: the eye represents the "...spelling of the initial of the word info..." He adds a further insight: a "centrality" concept concerning the iris of the eye. The respondent puts it as: "...the iris acts as the central point of the plaza where all knowledge concentrates..." This leads us directly to the next reason for using the eye as a symbol.

\section{(2) The Eye in its Function of Seeing}

One of the most unusual responses we receive is this remark: "...I have no idea how the eye was chosen..." Yet he later attributed as a possibility, the concept of "the mind's eye". Thus the key, perhaps unconscious thus all the more powerful reason for the choice of eye is in its function of seeing. Many of owners emphasize this as the reason for choosing the eye: photography, video production, web design, videoconferencing, research on tracking movements of the eye, technology related to eye gazing; film industry; visual communication, cryptography and biometrics. Thus the eye is utilized to portray this symbolically. Even more interestingly one respondent emphasizes his choice of the eye for "...stylization..." into a $\log$ for the fact that: "...the eye doesn't interpret the reality it sees, but it gives a sharp, selective focus to it..." Yet another respondent chose the eye after he had been "...thinking long and hard..." and as he puts it: "...I chose the eye logo as it represents a vision or insight into the work that we do...". The eye is employed here in a metaphorical role. 
Table 3. Process of Designing Eye Logo

\begin{tabular}{|c|c|c|c|c|c|}
\hline \multicolumn{6}{|c|}{ (i) Designer } \\
\hline & & Frequency & Percent & Valid Percent & Cumulative Percent \\
\hline \multirow{3}{*}{ Valid } & No & 26 & 48.1 & 51.0 & 51.0 \\
\hline & Yes & 25 & 46.3 & 49.0 & 100.0 \\
\hline & Total & 51 & 94.4 & 100.0 & \\
\hline Missing & & 3 & 5.6 & & \\
\hline \multicolumn{2}{|c|}{ Total } & 54 & 100.0 & & \\
\hline
\end{tabular}

\begin{tabular}{|c|c|c|c|c|c|}
\hline \hline \multicolumn{2}{|c|}{} & Frequency & Percent & Valid Percent & Cumulative Percent \\
\hline \multirow{3}{*}{ Valid } & No & 25 & 46.3 & 49.0 & 49.0 \\
\cline { 2 - 6 } & Yes & 26 & 48.1 & 51.0 & 100.0 \\
\cline { 2 - 7 } & Total & 51 & 94.4 & 100.0 & \\
\hline \multirow{2}{*}{ Missing } & & 3 & 5.6 & & \\
\hline
\end{tabular}

\begin{tabular}{|c|c|c|c|c|c|}
\hline & & Frequency & Percent & Valid Percent & Cumulative Percent \\
\hline \multirow{3}{*}{ Valid } & No & 37 & 68.5 & 72.5 & 72.5 \\
\hline & Yes & 14 & 25.9 & 27.5 & 100.0 \\
\hline & Total & 51 & 94.4 & 100.0 & \\
\hline Missing & & 3 & 5.6 & & \\
\hline \multicolumn{2}{|c|}{ Total } & 54 & 100.0 & & \\
\hline
\end{tabular}

Note: Statistical tables generated by SPSS

A far more demanding task is in seeing into the future.

This is the perspective that one respondent wishes to convey through his eye logo: "seeing" creatively and imaginatively but into a future scenario. A less demanding expectation upon the viewers is in the eye as metaphor for "...discernment..." Other respondents choose to qualify this "seeing" by adding the descriptive of "Minds" to the "Eye" as part of his logo so as to: "...express the concept of imagination...something which can be imagined through the process of creative thought..." Besides this, other qualifiers are put before the word eye to more accurately the work of the respondents. For example, the "Spinning" Eye emphasizes the 360 degrees spin photography undertaken by the photographers. Or in the case of "The Customer's" Eye, the intention of the respondents is to highlight the direction of their marketing consulting practices. That of emphasizing to their technology business clients to: “...focus their marketing efforts on their customer's interests rather than on their product features..." Thus in corporate branding there are very good, utilitarian explanations why certain words are being added to symbols. 
Overall, one trend is clear. Symbols are chosen often for their visual roles: achieving efficiency and effectiveness in communications. These analyses also suggest another deeper, psychological explanation: the deep need of owners to communicate with other people as exactly as possible what they are actually doing.

\section{(3) Eye as a Matter of Personal Circumstances}

\section{(i) Conscious Design}

Our statistical results suggest that half of the eye-logos are designed by the respondents themselves. This makes our sample an intriguing one for possible insights as to the rationale behind the choice of eye as a logo. We highlight specifically the most interesting comments, those that provide the personal circumstances leading to the decision for adopting the eye as logo. In one case, the respondent uses the very well-known Egyptian third eye, the Eye of Horus for branding which is an outcome of very personal circumstances. His key rationale is in these words:

“...lost vision in my right eye..."

Why Horus? As he had explained it as:

“...since like Horus I have only one eye..."

Then there is another who provided us with an almost mystical reason of why the symbol of eye is utilized. That it first appeared in a dream to the respondent's business partner when he was still a teenager. Then there are cases where, eye is a personification - the owner, as himself or herself. A female respondent offers exactly this explanation: she uses the "eye" as the word sounds like "I" - a personal ego, I and not just as a alphabet. In the sense that the logo is referring to herself: meaning "I". Similarly, in another instance, a respondent had "eye" incorporated as part of his name within the logo so as to make a statement about he himself:

\section{"...that I see or that I am observant..."}

This association of eye with being observant is found in yet another instance, where the respondent said "... The logo is my own..." He explained its role more as a personal reminder in his work: "...I use it to remind myself that I am to observe as clearly and unbiased as I can, as tolerant and kindly as I can..." In sharp contrast to such personal, conscious, even ego-centered approaches, there is also a respondent who reported diametrically the opposite.

\section{(ii) Unconscious, Emergence and Evolutionary}

A respondent reports that the logo emerges in design as resembling an "eye". This happens only after he had been using the design for a year. Even more intriguingly, is in the spontaneity in choice of the eye as symbol: “...I can only say it was artistic inspiration! It seemed right at the time..." Then for another it is a result of his client, a graphic designer. The client notices the uniqueness of his way of seeing as a photographer. It is this client who later develops the eye logo for him. Thus eye as symbol for a logo also happens as a matter of chance. This is reflected in the case of the logo, "Red Eye". For this respondent the term is used to reflect their working late into the night that resulted in the red eye syndrome. Then there is an evolutionary and deeply personal process in using the eye as logo: “...started as a tag... Originally, I signed underneath the eye with the letter
"I"...The disembodied eye sees without the distortions of the ego/mind..." Or in another case, it is of the logo reflecting the respondent's work habit: “... The idea of this eye is that I work from what I see around me. I carry a digital camera everywhere so I don't miss an interesting subject..."

These cases illustrate the sometimes deeply, in psychological terms, ego-centric rationale underlying the design of logos. At least for some owners the logo utilized in corporate branding have deep, psychological significances to them as individuals. And for a few, the eye symbol emerges only after significant periods of unconscious, meditative contemplations.

\section{(4) Integrating Eye with Other Symbols}

In this section we look at cases where the eye is integrated with other motifs and symbols as logo. In these cases, we find other symbols are added for clarity on what is to be communicated. These additional graphics, signs or symbols may yield interesting insights behind the psychology of the eye as symbol in corporate branding. For instance, a cross $(\mathrm{X})$ is being placed in the eye. According to respondent is to reflect the concept of being blind in the eye. In another case, the imagery of hands forming a frame around the pupil of the eye is for denoting the "...frame of vision..." And this, as explained by the respondent is just what "...a photographer might do when composing a shot..." Essentially the imagery adds specificity. Most intriguingly is in our finding of an eye logo where musical notes are being embedded. The respondent describes the imagery of dynamic musical notes: "...musical notes rolling across the eye..." [Italics added] According to the respondent who creates the logo, it depicts for him a psychological state of mind, one when one is highly creative. In his own words, he describes the state of being in terms of these: "...a synesthetic state of awareness and creativity..." This is consistent with the much oft-quoted belief that the eye is the window to the soul.

Besides musical notation, one respondent creates a logo by putting in a "...sine wave in the iris of the eye..." And his rationale is to create thereby a "...audio inter-visual logo..." Clearly the goal is to for the logo to reflect two of our most powerful human senses: visual and audio. Two of our respondents added the globe into the eye. Each however has his own reasons. For one, his objective is to stress the international nature of their business in technology assessment. In the other, the meaning of "...global...." is for the respondent "...many perspectives on world issues, not just one..." So the same symbol - globe - may have very different significances and meanings for different owners. We find one logo where the eye is set onto the outline form of the State of New York. The explanation is that it is derived from the television show, the Twilight Zone. In another instance, one respondent placed the eye inside a square so that the logo in corporate branding "...hinted at elements of (a) technology (b) originality (c) humor and (d) memorability..." And in another instance, the eye is deliberately encased in up-raised hands to signify the sense of celebration. In another, an eye set within roaring flames. The flames were to reflect the fact that their company is "...fiery or passionate about design..." And the eye was chosen as representing “...either...our eyes while at work, or it can also designate how others will feel after looking at our work..." The eye as aflame symbolizes a 


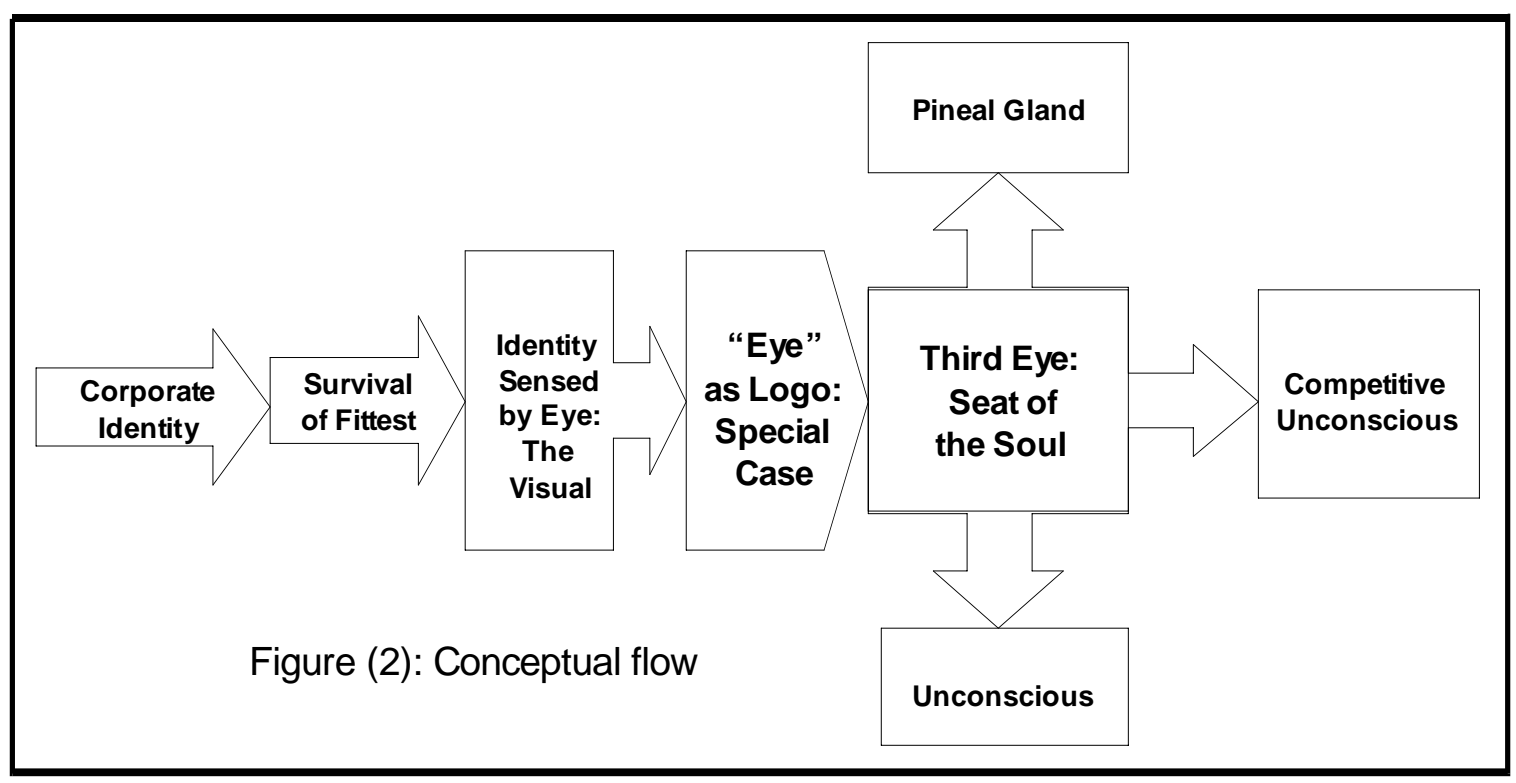

Fig. (2). Conceptual flow.

certain exalted psychological state of being. Most interestingly and consistent too with the symbolic use of "fire", the color of the eye was chosen by the female respondent for a very personal reason: “...I had just fallen madly in love with a guy..." Reinforcing the eye as the window to the human soul, she adds that "...His eyes were something that I couldn't forget and that is how I came up with the color of the eye..."

\section{(5) More than Meet the Eye}

Here we explore unusual comments from respondents. For some the eyes utilized as part of their logos are not human but godly, as one respondent asserts: "...The eye is a stylized Mexican Eye of God..." In another case, the logo is an abstraction of Eye of the Egyptian Horus: “...derived from the ancient Egyptian Eye of Horus which is a symbol of protection, and also represents wisdom and prosperity....we created a more simplistic, modernized version of it..." There is an even more intriguing explanation of the eye for corporate branding: a belief in the Third Eye (see earlier discussion). According to one respondent who provides feng shui advice, he uses an imaginary, Third Eye to "...envision auspicious energy flow..." Relating to the same metaphor, another respondent explains his choice of the eye as follows: "...The name Third Eye comes from the pineal eye some reptiles have..." One respondent prefers the eye for its representation as "... an awakened state of consciousness..."

The most interesting story of all is in how the eye was retained as corporate logo when the original $\log$, the face of a woman, is slowly eliminated. Through this evolutionary process of selection and adaptation, the final logo is reduced to its core essence. The final logo for communicating: the eye. We argue that this case illustrates just how the "eye" here is in essence communicating, the human soul. Following Rene Descartes, it is not the ordinary human eyes but the "third eye", possibly the pineal gland, proverbial seat of the soul.
Perhaps the pineal gland, third eye is the root to our unconsciousness. Possibly, the source or biological node that is integral to our human instinctive behavior. Maybe it is the root to our instinctual drive in surviving by adapting to ever changing environment. For large corporations, it is to sustain their presence through corporate e-identity efforts in this Darwinian, hypercompetitive environment. In summing up, we turn to discuss the competitive unconscious.

\section{The Competitive Unconsciousness}

We frame this discourse by posing the question: what is the rationale for corporate e-identity (see Fig. 2) below)? In particular, we ask why already reputable, huge (dinosaur-like in size) corporations still 'splurge' advertising dollars to emphasize their presence in the jungle-like, marketplace. One plausible argument is that these highly successful, adaptable organizations realize survival in this hypercompetitive environments do not depend on size. That it is ultimately the survival of the fittest through continual adaptations by innovative, winning product placements to ever changing marketplace. Agreeing with Jonathan Schroeder, the competitive edge is in strong visual presence of corporate e-identity, capturing attention, i.e. through the visual before the sales. Since e-identity is so visual bound (see, e-identity sensed by the eye), we then explored eye in logos. A journey that led us towards uncovering simultaneously (see flowchart): "third eye" as seat of the soul, it's possible biological, pea-size organ and role of the unconscious in corporate e-identity strategy.

In the process we have, borrowing from Ellenberger, probably re-discovered an underlying psyche in us, the competitive unconscious. Here we close this paper by arguing for the possibility of competitive unconscious as the underlying psychological rationale in choices of symbols in corporate branding. These are some of our reasons for making such a proposition. Firstly, we have found that the symbol chosen often has a long, even deeply rooted association with corporate, business or an entrepreneur's past, competi- 
tive successes. This particularly so when business owners explained their utilization of the eye symbol as visual means to remind themselves of their past successes. If so a symbol utilized in branding may in effect have value of reassurances: reassuring owners of their own competitive edge. In other words, a chosen symbol may have roles beyond mere communication. The symbol is there to boost psychologically the confidence of business owners and not always as a tool for market communication. Secondly, we consider the preoccupation of some of our corporate branders in communicating via the eye logo as exactly as possible the kind of activity they are involved in. One interpretation is that the owners desired highly, communicative effectiveness. A deeper, perhaps even more profound reason may lie in dire necessity of owners to survive through ensuring a strong visual presence. Here, the analogy with nature seems to make sense: the diversity of colours of flowers. Such diversity is precisely for flowers to signal visually their presence. And in the process attract the bees to ensure their continued survival. Owners who reinforce a given say eye-logo with other elements may just be exactly that of efficiently attracting the right kind of customers (bees). If this is indeed the case, then these arguments add support for the much broader explanation, one of a competitive unconscious that is at work. Thirdly, some owners choose the eye as symbols for "powers" beyond ordinary human vision. Logically, competitive successes demand certain capabilities. So the logo as designed may also be symbolically reminding the owners of their special skills, talents and abilities. Even though a logo is ostensibly and consciously intended for their customers, yet symbols can be powerful reminders to owners on why they are still surviving in hypercompetitive markets. That it is due to their extraordinary capabilities (example of having the right vision), they could stay ahead of their competitors. Our argument of a competitive unconscious ought not to surprise. Of all our human senses, it clearly has to be the eye that is the most vital from our origin to our struggle for survival (see Darwin's original work (1859)). Hence there is the critical role for the visual in branding for presence in corporate e-identity strategy.

\section{REFERENCES}

Arnheim, Rudolf (1974), Art and visual perception: a psychology of the creative eye, University of California Press.

Balmer, J.M.T. (2001), Corporate e-identity, corporate branding and corporate marketing, European Journal of Marketing, 35: 248-291.

Bonafoux, Pascal (1992), Van Gogh: the passionate eye, Thames and Hudson: London.

Blumenfeld, Eriwn (1999), Eye to I: the autobiography of a photographer, Thames and Hudson: London.

Carus Carl Gustav, (1846) Psyche, zur Entwicklungsges chichte der Seele (Pforzheim: Flammer and Hoffman).
Darwin C. (1859) On the Origin of Species, Murray: London.

Descartes, R., (1637), La dioptrique, in: Descartes, R., Discours de la méthode, Leyden.

Descartes, R., (1649), Les passions de l'âme, Amsterdam (In French).

Dessoir Max, (1890) Das Doppel-Ich, Gunther: Leipig.

Drabble, Margaret (1973), The needle's eye, Penguin.

Duchowski, Andrew T. (2003), Eye tracking methodology: theory and practice, Springer and Verlag: London.

Ellenberger Henri F., (1970) The Discovery of the Unconscious, 1970, Basic Books: New York.

Felix E. Goodson, (2003) The Evolution and Function of Cognition, Lawrence Erlbaum Associates, New Jersey.

Foo CT (2001), Designing e-logos in corporate e-identity strategy, Brand Management, Vol. 8(4), pp 334-345.

Foo CT, (2003) Visualising Complexity in Corporate E-identity on the Internet, Corporate Communications: An International Journal, Vol. 8 (1), pp. 11-17.

Foo CT, (2003) Child of the Internet: Perceptions of Creativity in eIdentities, CyberPsychology and Behavior, Vol. 6(2), pp. 195-199.

Foo CT (2003), Enabling Symbolism for Communicating Performance, Corporate Communications: An International Journal, Vol. 8(4), pp. 241-254.

Foo C.T. and Lowe, Andy (1991), Modelling for Corporate E-identity Studies: Case of E-identity as Communications Strategy, Corporate Communications: an International Journal, Vol. 4(2), pp 89-92.

Foo CT, Lowe A. and Foo CT (2001), Corporate E-identity Strategy: Empirical Analyses of Major Asean Corporations, Corporate Communications: An International Journal, Vol. 6(3), 137-143.

Greenberg Jan (1991), Painter's eye: learning to look at contemporary American art, Delacorte Press.

Hall, T.S. (1972), Treatise of Man, Harvard University Press: Massachusetts.

Kapferer J N (2004) Strategic Brand Management: Creating and Sustaining Brand Equity Long Term, Kogan Page: London.

Mauldin John (2004), Bull's eye investing: targeting real returns in a smoke and mirrors market, John Wiley, New Jersey.

Mora, Gilles (2004), Walker Evans: the hungry eye, Thames \& Hudson: London.

Muir Robin (2002), A Maverick eye: the street photography of John Deakin, Thames and Hudson: London.

Pamela W. Henderson, Joan L. Giese and Joseph A. Cote (2004), Impression Management Using Typeface Design, Journal of Marketing, 68 (4), 60-72.

Pamela W. Henderson, Joseph A. Cote, Siew Meng Leong and Bernd Schmitt (2003), Building Strong Brands in Asia: Selecting the Visual Components of Image to Maximize Brand Strength, International Journal of Research in Marketing, 20(4), 297-313.

Schroeder Jonathan (1998) Consuming Representation: A Visual Approach to Consumer Research" in Barbara B. Stern (ed.) Representing Consumers: Voices, Views and Visions, New York: Routledge, 193-230.

Schroeder, Jonathan (2002) Visual Consumption, Routledge: London.

Schultz M, Hatch M J and Larsen M, (2000) The Expressive Organization, Oxford University Press: Oxford.

Theodore Flournoy, "Genese de quelques pretendus messages spirites", Annales des Sciences Psychiques IX (1899), 99-216 Trollope Society: London.

Theodor Lipps III (1896), Internationaler Congress Fur Psychologie in Muchen, pp. 146-164, Munich: JF Lehmann).

Trollope, Anthony (1993), An eye for an eye, Trollope Society: London.

White, Patrick (1975), The eye of the storm, Penguin Books: London. 